\title{
PERBANDINGAN UJI TOKSISITAS \\ FITOESTROGEN PADA GINJAL TIKUS (SPRANGUE DAWLEY) YANG DIINDUKSI DAIDZEIN DAN AIR PERASAN UMBI BENGKUANG (PACHYRHIZUS EROSUS)
}

\author{
Farizha Irmawati ${ }^{1 \cdot}$ Cicilia Novi Primiani ${ }^{2}$ \\ IKIP Budi Utomo Malang, IKIP PGRI Madiun \\ Email: Farizha99@gmail.com.
}

\begin{abstract}
Phytoestrogens a compound commonly found in the environment and are known to disrupt the balance of animal and human hormonal system phytoestrogens can accumulate in the body, in principle to the use of fitofarmaka broadly, require preclinical trials to determine the safety level for sure. Toxicity is the innate nature of a substance, form and level of toxic manifestations in an organism, the real factor is the dose and duration of exposure to the compound in the organ. Fresh yam tubers (Pachyrhizus erosus) that contain phytoestrogens that can be used safely, effectively and efficiently, it is necessary to perform preclinical testing with phytoestrogens toxicity analysis, to determine the level of safety for sure. The method used is an experimental research study aimed to compare the toxicity of phytoestrogens, daidzein and the juice of yam tubers (Pachyrhizus erosus). The study design of experiments conducted using completely randomized design (CRD). The test results by using current statistical Pairs T-test, showed no real difference amount tubular necrosis and glomerular cells, treatment with synthetic daidzein administration and the juice of yam tubers (Pachyrhizus erosus). So the results of this study concluded that phytoestrogens yam tubers (Pachyrhizus erosus) not toxic.
\end{abstract}

Keyword: Comparative toxicity Phytoestrogens, Daidzein, Juice Water Yam tubers (Pachyrhizus erosus).

Abstrak-Fitoestrogen suatu senyawa yang banyak ditemukan di lingkungan sekitar dan diketahui dapat mengacaukan keseimbangan sistem hormon binatang maupun manusiaFitoestrogen dapat terakumulasi dalam tubuh, secara prinsip untuk penggunaan fitofarmaka secara luas, memerlukan uji praklinik untuk mengetahui tingkat keamanannya secara pasti. Toksisitas merupakan sifat bawaan suatu zat, bentuk dan tingkat manifestasi toksiknya pada suatu organisme, faktor yang nyata adalah dosis dan lamanya paparan senyawa pada organ. Umbi bengkuang segar (Pachyrhizus erosus) yang mengandung fitoestrogen agar dapat digunakan secara aman, efektif dan efisien, maka diperlukan uji praklinis dengan melakukan analisis toksisitas fitoestrogen, untuk mengetahui tingkat keamanannya secara pasti. Metode yang digunakan penelitian ini merupakan penelitian eksperimen yang bertujuan untuk mengetahui perbandingan toksisitas fitoestrogen, pada daidzein dan air perasan umbi bengkuang (Pachyrhizus erosus). Rancangan penelitian eksperimen dilakukan menggunakan Rancangan Acak Lengkap (RAL). Hasil uji statisik dengan menggunakana T-test Pairs, menunjukkan tidak ada perbedaan nyata jumlah sel nekrosis tubulus dan glomerulus, dengan perlakuan pemberian daidzein sintetis dan air perasan umbi bengkuang (Pachyrhizus erosus). Sehingga hasil penelitian ini dapat disimpulkan bahwa fitoestrogen umbi bengkuang(Pachyrhizus erosus) tidak bersifat toksik.

Kata kunci: Perbandingan Toksisitas Fitoestrogen, Daidzein, Air Perasan Umbi Bengkuang (Pachyrhizus erosus).

\section{PENDAHULUAN}

Obat tradisional biasanya terdiri dari bahan alami, secara tunggal ataupun sebagai ramuan dari berbagai macam bahan. Obat tradisional dengan formula yang sama ternyata dapat digunakan untuk pengobatan berbagai macam penyakit yang berbeda oleh satu daerah dengan daerah yang lain. Hal ini dapat disebabkan karena dalam satu tanaman terdapat berbagai senyawa kimia yang mempunyai khasiat yang berbeda sehingga dapat digunakan untuk berbagai indikasi. Jamu merupakan 
ramuan tradisional yang belum teruji secara klinis, sedangkan obat herbal yang terstandar adalah yang sudah lulus uji pra klinis. Sementara fitofarmaka adalah obat herbal yang sudah lulus uji klinis. Jumlah terbesarnya memang adalah jamu. Meskipun sudah banyak digunakan, tapi belum dilakukan uji secara klinis.

Fitofarmaka yang telah melalui serangkaian uji praklinis dan uji klinis siap digunakan dalam sistem pengobatan modern sejajar dengan obat-obat kimia. Jamu-jamu akan menjadi obat herbal terstandar jika telah melewati uji praklinik terhadap hewan coba, berupa uji toksisitas. Uji ini penting dilakukan untuk melihat reaksi bahan kimia tertentu terhadap kehidupan. Jika lulus dengan baik, obat ini dapat dikatakan aman untuk dikonsumsi (Nurkhasanah, 2006).

Tumbuhan menghasilkan berbagai bahan untuk manusia, baik yang menguntungkan maupun yang merugikan. Salah satu bahan yang dapat merugikan adalah fitoestrogen. Fitoestrogen suatu senyawa yang banyak ditemukan di lingkungan sekitar dan diketahui dapat mengacaukan keseimbangan sistem hormon binatang maupun manusia (Gultekin, 2006). Fitoestrogen dapat terakumulasi dalam tubuh, secara prinsip untuk penggunaan fitofarma secara luas, memerlukan uji praklinik untuk mengetahui tingkat keamanannya secara pasti.

Toksisitas merupakan sifat bawaan suatu zat, bentuk dan tingkat manifestasi toksiknya pada suatu organisme, faktor yang nyata adalah dosis dan lamanya paparan senyawa pada organ. Umbi bengkuang segar (Pachyrhizus erosus) yang mengandung fitoestrogen agar dapat digunakan secara aman, efektif dan efisien, maka diperlukan uji praklinis dengan melakukan analisis toksisitas fitoestrogen, untuk mengetahui tingkat keamanannya secara pasti. Organ yang berperang langsung dalam efek negatif atau merugikan suatu senyawa yaitu organ ginjal.Ginjal adalah suatu organ yang secara struktural kompleks dan berkembang untuk beberapafungsi, diantaranya: ekskresi produk sisa metabolisme, pengendalian air dan garam, pemeliharaankeseimbangan asam dan basa, serta sekresi berbagai hormon dan autokoid (Cotran et al., 2007).

Penelitian ini bertujuan untuk mengetahui gambaran histopatologik nekrosis pada ginjal tikus betina sprangue dawley yang diinduksi daidzein dan perasan umbi bengkuang (Pachyrhizus erosus).

\section{METODE PENELITIAN}

Penelitian ini di laksanakan di Laboratorium LSIH Universitas Brawijaya dan Laboratorium Mikrotek FMIPA Universitas Negeri Malang, dengan mengamati organ ginjal, pada sel glomerulus dan tubulus yang mengalami nekrosis.Pengujian komponen dalam umbi Bengkuang (Pachyrizus erosus) dengan metode analisis High Performance Liquid Chromatography (HPLC), dilakukan di Laboratorium Kimia Universitas Muhammadiyah Malang.

Metode yang digunakan penelitian ini merupakan penelitian eksperimen yang bertujuan untuk mengetahui perbandingan toksisitas fitoestrogen, pada daidzein dan air perasan umbi bengkuang (Pachyrhizus erosus). Rancangan penelitian eksperimen dilakukan menggunakan Rancangan Acak Lengkap (RAL).

\section{Pelaksanaan Penelitian}

\section{a. Pembuatan larutan daidzein}

Langkah awal yang dilakukan untuk membuat larutan daidzein, dosis daidzein murni yang diberikan setara dengan kadar daidzein 1,5 $\mathrm{ml}$ air perasan umbi bengkuang 
sebesar 20,188 mg yang disesuaikan dengan dengan berat badan tikus lalu dilarutkan ke dalam akuades menjadi $1,5 \mathrm{ml}$.

\section{b. Perasan umbi bengkuang (Pachyrhizus erosus)}

Umbi bengkuang sebanyak 100 $\mathrm{g}$ dicuci bersih dan tidak dikupas kulitnya, selanjutnya dihaluskan dengan parutan dan disaring. Uji komponen senyawa umbi bengkuang dilakukan analisis menggunakan metode analisis High Performance Liquid Chromatography (HPLC). Air perasan umbi bengkuang (Pachyrhizus erosus) diambil $1,5 \mathrm{ml}$ yang didalamnya terdapat daidzein sebanyak 20,188 mg/100 gram yang diuji HPLC saat uji pendahuluan.

\section{c. Pemeliharaan tikus Betina (Sprangue dawley)}

Hewan coba yang digunakan dalam penelitian ini adalah tikus betina sprangue dawley, didapat dari Universitas Gajah Mada Yogyakarta dalam kondisi sehat, kisaran umur 5 bulan, yang berjumlah 10 ekor denganrentang berat badan 160-210 gram, yang dipelihara dalam kandang pemeliharaan tikus LSIH Universitas Brawijaya Malang.

Tikus dilakukan proses aklimatisasi selama 14 hari sebelum perlakuan dengan menempatkan dalam kandang pemeliharaan dilengkapi dengan easy flow. Dipelihara dalam kandang selama 28 hari dan diberikan perlakuan setiap hari diinduksi langsung ke dalam lambung dengan menggunakan alat sonde (gavage tube), sebanyak satu kali dalam sehari selama 28 hari, pada 5 ekor tikus dengan disonde larutan daidzein, 5 ekor tikus disonde dengan air perasan bengkuang (Pachyrhizus erosus). Pemberi makan dan minum ad libitum, mengganti sekam dan menimbang bobot tikus seminggu sekali.

\section{d. Pembedahan dan Pengambilan Organ}

Tikus sprangue dawley yang sudah 28 hari diberi perlakuan dengan pembetian larutan daidzein dan air perasan umbi bengkuang (Pachyrhizus erosus) maka dilakukan tikus didislokasi leher pada hari ke29 dilakukan pembedahan melalui abdomen/rongga perut untuk pengambilan organ ginjal.

\section{e. Pembuatan Preparat}

Sebelum melakukan analisis toksisitas pada organ ginjal, terlebih dahulu dilakukan pembuatan preparat histologi dan dilanjutkan dengan pewarnaan hematoksilin eosin.Pembuatan irisan preparat histologis meliputi beberapa tahap, yaitu tahap fiksasi, tahap dehidrasi, tahap cleaning, tahap infiltrasi, tahap embedding, tahap pengirisan dan tahap pewarnaan (Lampiran 3).

\section{f. Pengamatan Preparat dan Pengumpulan Data}

Preparat yang sudah diwarnai kemudian diamati dengan mengunakan perangkat komputer yang sudah dilengkapi dengan lensa okuler untuk mempermudah pengamatan. Pengamatan pada organ ginjal dengan mengamati tubulus dan glomerulus, dengan menghitung jumlah sel yang mengalami nekrosis dengan 3 kali ulangan pengamatan pada setiap organ ginjal.

\section{g. Analisis Data}

Data kemudian dianalisis secara statistik menggunakan uji $\mathrm{T}$ 
berpasangan (T-test Pairs) dengan taraf uji $5 \%$. Dalam penelitian ini analisis data dilakukan dengan menggunakan program SPSS versi 21.

\section{HASIL PENELITIAN}

Sel yang mengalami nekrosis pada jaringan glomerulus dan tubulus 1 . kontortus distal, diamati dengan menggunakan mikroskop, diulang sebanyak 3 kali ulangan di setiap lokasi jaringan, pada perlakuan dengan pemberian daidzein dan pemberian air perasan bengkuang (Pachyrhizus erosus) dipaparkan pada Tabel 1, 2 dan Gambar

Tabel 1 Rata-rata nekrosis pada jaringan Glomerulus dan Tubulus Kontortus Distal.

\begin{tabular}{ccccc}
\hline \multirow{2}{*}{ NoSampel } & \multicolumn{2}{c}{ Glomerulus } & \multicolumn{2}{c}{ Tubulus Kontortus Distal } \\
\cline { 2 - 5 } & $\begin{array}{c}\text { Air Perasan } \\
\text { Bengkuang }\end{array}$ & Daidzein & $\begin{array}{c}\text { Air Perasan } \\
\text { Bengkuang }\end{array}$ & Daidzein \\
\hline 1 & 11.44 & 23.22 & 13.44 & 19.66 \\
2 & 8.44 & 22.88 & 11.77 & 19.77 \\
3 & 7.55 & 17.66 & 16.99 & 26.66 \\
4 & 7.77 & 18.33 & 18.33 & 21.88 \\
5 & 9.55 & 19.10 & 11.66 & 29.66 \\
Rata-rata & 8.95 & 18.04 & 14.44 & 23.53 \\
\hline
\end{tabular}

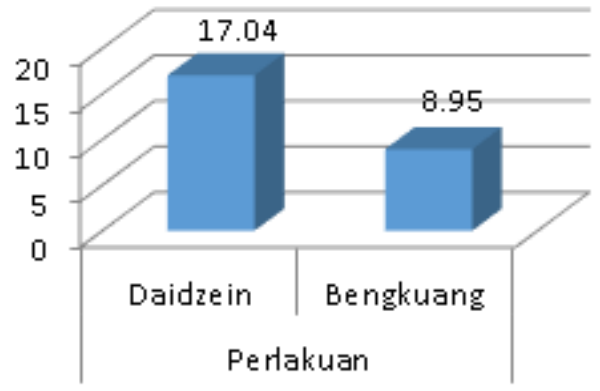

Gambar 1 Perbandingan rata-rata sel yang mengalami nekrosis pada glomerulus dengan perlakuan pemberian daidzein sintetis dan air perasan umbi bengkuang (Pachyrhizus erosus).

Tabel 2 Uji T-test Pairs perlakuan pemberian daidzein sintetis dan air perasan umbi bengkuang (Pachyrhizus erosus) terhadap Glomerulus Ginjal.

\begin{tabular}{llll}
\hline & N & correlation & Sig \\
\hline $\begin{array}{l}\text { Pair 1 } \\
\text { Bengkuang \& Daidzein }\end{array}$ & 5 & 0,286 & 0,641
\end{tabular}

Keterangan: Nilai sig $(0,641)>0,005$; tidak ada perbedaan nyata perlakuan terhadap nekrosis

Uji statistik menunjukkan tidak ada perbedaan nyata jumlah sel nekrosis glomerulus disajikan pada Tabel 2.

Hasilujistatisikdenganmenggunakana T-test Pairs, menunjukkan tidak ada perbedaan nyata jumlah sel nekrosis glomerulus dengan perlakuan pemberian daidzein sintetis dan air perasan umbi bengkuang (Pachyrhizus erosus,
Mengamati sel yang mengalami nekrosis pada jaringan Tubulus Kontortus Distal, dengan menggunakan mikroskop yang diulang 3 ulangan di setiap lokasi jaringan, pada perlakuan dengan pemberian daidzein dan pemberian air perasan bengkuang (Pachyrhizus erosus) dipaparkan pada Gambar 2 dan Tabel 3. 


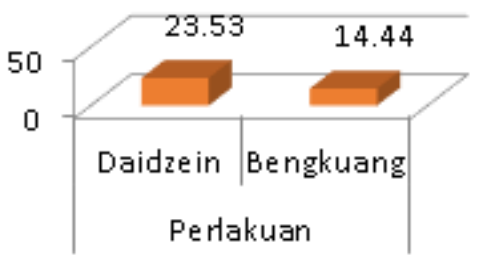

Gambar 2 Perbandingan rata-rata sel yang mengalami nekrosis pada Tubulus Kontortus Distal dengan perlakuan pemberian daidzein sintetis dan air perasan umbi bengkuang (Pachyrhizus erosus).

Tabel 3 Uji T-test Pairs perlakuan pemberian daidzein sintetis dan air perasan umbi bengkuang (Pachyrhizus erosus) terhadap Tubulus Ginjal.

\begin{tabular}{|l|c|l|l|}
\hline & N & correlation & Sig \\
\hline $\begin{array}{l}\text { Pair 1 } \\
\text { Bengkuang \& Daidzein }\end{array}$ & 5 & $-0,029$ & 0,93 \\
\hline
\end{tabular}

Keterangan: Nilai sig $(0,93)>0,005$; tidak ada perbedaan nyata perlakuan terhadap nekrosis tubulus.

Uji statistik menunjukkan tidak ada perbedaan nyata jumlah sel nekrosis glomerulus disajikan pada Tabel 3.

Hasil uji statisik dengan menggunakana T-test Pairs, menunjukkan tidak ada perbedaan nyata jumlah sel nekrosis tubulus dengan perlakuan pemberian daidzein sintetis dan air perasan umbi bengkuang (Pachyrhizus erosus).

\section{PEMBAHASAN}

Saat ini banyak diteliti dampak positif, umbi bengkuang (Pachyrhizus erosus) mengandung senyawa isoflavon. Isoflavon merupakan salah satu senyawa metabolitsekunder yang disintesis oleh tanaman(Prawiroharsono,2007). Senyawa ini termasuk kelompok flavonoid yangmempunyaiaktivitasestrogenikyang potensial. Jikadiperhatikan strukturnya, tampak ada kemiripan denganhormon estrogen (Robinson, 1995). Struktur kimia isoflavon menyerupai 17 $\beta$-estradiol (Gruber et al., 2002; Delmonte dan Rader, 2006; dan Barlow et al,. 2007), sehingga Pachyrhizus erosus sering disebut sebagai kelompok tanaman fitoestrogen (Urasopon et al., 2008).

Tetapi belum ada penelitian yang menguji dampak negatif penggunaan umbi bengkuang (Pachyrhizus erosus) sebagai sumber fitoestrogen, sehingga dilakukan analisis toksisitas fitoestrogen, agar dapat digunakan sebagai sumber fitoestrogen secara efektif dan aman. Secara farmakokinetik, zat yang masuk ke dalam tubuh akan mengalami absorbsi, distribusi, metabolisme dan eksresi. Ginjal merupakan organ eksresi utama yang sangat penting, untuk mengeluarkan sisasisa metabolisme tubuh, sehingga sering mengalami kerusakan jika terpapar oleh zat-zat yang bersifat toksik, sebagai organ yang berfungsi sebagai: 1) membersihkan tubuh dari bahan sisa-sisa metabolisme, 2) mengontrol volume dan komposisi cairan tubuh, 3) memelihara kestabilan sel.

Pengujian toksisitas fitoestrogen dengan pengujian sub kronik, dilakukan pada hewan coba dengan pelakukan pemberian air perasan umbi bengkuang bengkuang (Pachyrhizus erosus) dan daidzein sintetis selama 28 hari, pada hari ke-29 didislokasi untuk diambil organ ginjal. Selanjutnya pengamatan organ ginjal yang mengalami nekrosis, pada jaringan glomerulus dan tubulus sebagai salah satu bukti kerusakan organ ginjal. Unit fungsional dasar ginjal adalah nefron, sebagai regulator air dan zat 
terlarut terutama elektrolit dalam tubuh dengan menyaring darah, kemudian mereabsorbsi cairan dan molekul melalui kapiler dan masih diperlukan oleh tubuh. Nefron terdiri dari sebuah komponen korpukskula malpigi yang dilanjutkan oleh saluran-saluran (tubulus), pada setiap korspukula mengandung kapiler darah yang disebut glomerulus (Champbell, 2010). Nekrosis merupakan kematian sel akibat adanya kerusakan sel akut, kematian sel terjadi secara tidak terkontrol.

Hasil pengujian toksisitas subkronik atau jangka pendek fitoestrogen bengkuang (Pachyrhizus erosus) dan daidzein, berdasarkan rerata sel yang mengalami nekrosis dengan perlakuan pemberian daidzein dan perlakuan pemberian air perasan umbi bengkuang (Pachyrhizus erosus), jaringan glomerulus dan tubulus. Hasil penelitian pengujian toksisitas sub-kronik atau jangka pendek fitoestrogen bahwa fitoestrogen umbi bengkuang bersifat toksiksisitasnya rendah, sebaliknya dengan larutan daidzein sintetis yang bersifat toksik dengan pengamatan mikroskopis. Keuntungan memanfaatkan bahan asal tanamanan (herbal) antara lain, toksisitasnya rendah, dan sedikit menimbulkan efek samping (Hernawati, 2009).

Bahan alam yang salah satunya umbi bengkuang(Pachyrhizus erosus) yang diberikan dalam bentuk kasar (crude material) akan bersifat lebih baik dibandingkan bahan sintetis/senyawa tunggal hasil isolasi. Adanya kompleksitas senyawa bahan alam menjadikan bahan alam dapat bekerja dalam tubuh dengan prinsipkeseimbangan (balancemetabolism). Formulasi kompleksitas senyawa bahan alam merupakan konsep terintegrasi dalam jaringan biologi, sehingga tidak terjadi prinsip kerja satu senyawa dengan satu target biologi (Primiani., 2013).

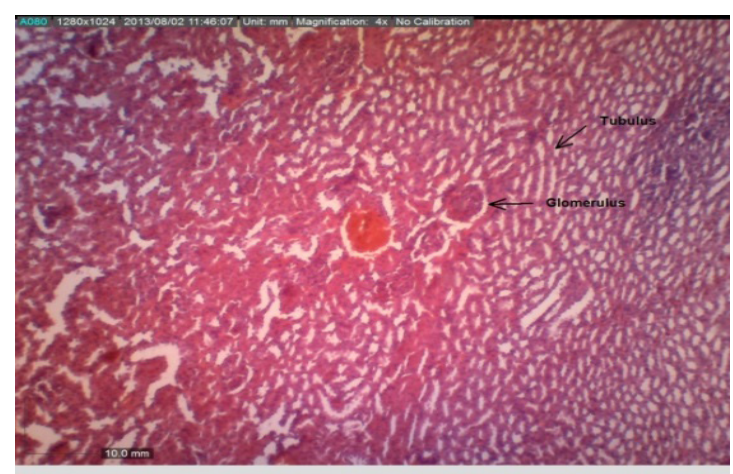

Gambar 4 Tubulus dan glomerulus (Foto: Dokumentasi Pribadi)

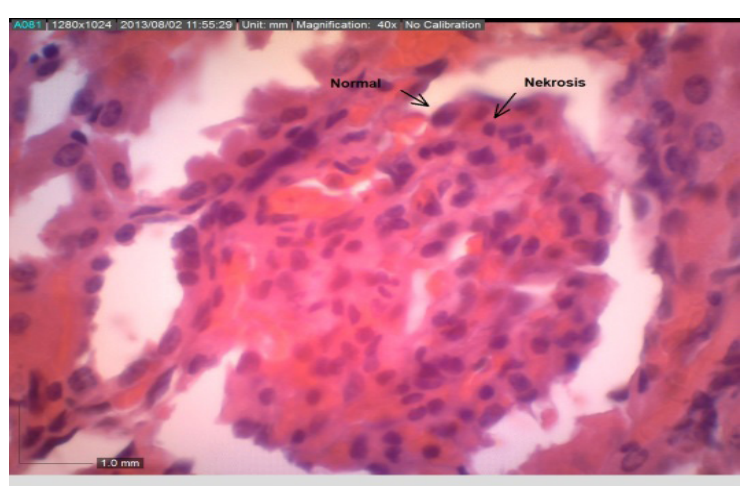

Gambar 5 sel normal (kiri) dan yang mengalami nekrosis (kanan). (Foto: Dokumentasi Pribadi)

\section{KESIMPULAN \& SARAN}

\section{Kesimpulan}

Pada perlakuan pemberian fitoestrogen umbi bengkuang (Pachyrhizus erosus) sel glomerulus yang mengalami nekrosis lebih sedikit dibandingkan dengan tikus betina Sprague dawley yang dengan perlakuan pemberian larutan daidzein sintetis berdasarkan pengamatan mikroskopis, sedangkan hasil uji statisik dengan menggunakana T-test Pairs, menunjukkan tidak ada perbedaan nyata jumlah sel nekrosis tubulus dengan perlakuan pemberian daidzein sintetis dan air perasan umbi bengkuang (Pachyrhizus erosus).

Sehingga hasil penelitian ini dapat disimpulkan bahwa fitoestrogen umbi bengkuang tidak bersifat toksik, sebaliknya dengan larutan daidzein sintetis yang bersifat toksik. 


\section{Saran}

a. Materi uji toksisitas bahan alam mencakup fitoestrogen pada bahan alam yang lainnya.

b. Dilakukan uji lanjutan berupa ujii karsinogenik, untuk mengetahui apakah air perasan umbi bengkuang (Pachyrhizus erosus) berpotensi menimbulkan kanker jika dikonsumsi jangka panjang.

\section{DAFTAR RUJUKAN}

Champbell, A.N., J.B. reece, \& L.G. Mitchell. 2010. Biologi edisi ke-8. Jilid

3. Jakarta: Erlangga.

Frandson, R. D. 1996. Anatomi dan Fisiologi Ternak, Alih Bahasa Oleh Srigandono, B. Dan Praseno, K. UGM Press. Yogyakarta, hal. 680689.

Frandson, R.D., 1992. Anatomi dan Fisiologi Ternak. Gajah Mada University-Press. Yogyakarta.

Ganong, W. F. 1997. Buku Ajar Fisiologi Kedokteran (diterjemahkan oleh Djauhari Widjajakusumah, Dewi Irawati, Minarma Siagian, Dangsina Moeloek, dan Brahma U. Pendit). Jakarta: Penerbit Buku Kedokteran EGC.

Glover A. and Assinder S.J. 2006. Acute exposure of adult male rats to dietary phytoestrogen reduces fecundity and alters epididymal steroid hormon receptor expression. Jour. Endoc. 189: 565-573.

Gruber, C.J., Tschugguel, W., Schneeberger, C., Huber, J.C. 2002. Production and Actions of Estrogens. The New England Journal of Medicine, (Online), 346(5):340-352, (http:// www.nejm.org/doi/pdf.10.1056/ NEJMra000471, diakses 10 Maret 2014).

Guyton, A. C. 1990. Fisiologi Manusia dan Penyakit, Alih Bahasa Oleh Andrianto, R. EGC. Jakarta, hal. 741, 752.

Guyton, A.C. \& Hall,J.E. 2006. Buku Ajar Fisiologi Kedokteran. Terjemahan oleh Luqman Yanuar Rachman. 2007. Jakarta: EGC Buku Kedokteran.

Guyton, A.C., 2000. Textbook of Medical Physiology tenth edition, WB Sounders Company ; 81: 1283-1302.

Guyton,Artur C. 1995. Buku Ajar Fisiologi Kedokteran. Jakarta: EGC

Hernawati, 2009. Perbaikan Kinerja Reproduksi Akibat Pemberian Isoflavon dari Tanaman Kedelai,Jurusan Pendidikan Biologi FMIPA Universitas Pendidikan Indonesia Bandung.

Heyne, K. 1987. Tumbuhan Berguna Indonesia III. Yayasan Sarana Wana Jaya. Jakarta. Hal. 1460-1462

Hugges I,Woods HF, 2003. Phytoestrogen and Health.London : Committe on Toxicity of Chemicals in Food,Consumer Product and The Environment.

Junqueira, et al., 2012. Histologi Dasar edisi 12 (alih bahasa dr. Frans Dany). Jakarta: Penerbit Buku Kedokteran EGC.

Khoirina, D. \& Wahyuni D., 2005. Isolasi dan Identifikasi Senyawa Flavonoid dalam Rimpang Temu Ireng (Curcuma aeruginosa Roxb.) Biofarmasi 3 (1): 32-38, ISSN: 16932242.

Kumala Sari, 2006. Pemanfaatan Obat Tradisional dengan Pertimbangan Manfaat dan Keamnannya. Majalah Ilmu Kefarmasian, Vol. III, No.1, April 2006, 01 -07ISSN : 1693-9883.

Lokakarya Tanaman Obat, 2012. 
Tumbuhan Bahan Pestisida Nabati.

Lukitaningsih, E. 2009. The Exploration of Whitening and Sun Screening Compounds in Benguang Roots (Pachyrhizus erosus.Disertasi, Wurzburg: Bayerischen Julius Maximillians University.

Malole MBM, Pramono CSU. 1989. Penggunaan Hewan-hewan Percobaan di Laboratorium. Departemen Pendidikan dan Kebudayaan, Dirjen Pendidikan Tinggi, Pusat Antar Universitas Bioteknologi. Bogor: IPB Press.

Murkies, Alice, et. al.1998. Phytoestrogens. The journal of Clinical Endocrinology $\mathcal{E}$ Metabolism Vol. 83, No 2, p 297-303.

Myers $\mathrm{P}$ and Armitage D. 2004. Rattus norvegicus (on-line), animal diversity.web.http:// animaldiversity.ummz.edu/site/ accounts/information/rattus_ norvegicus.html, diakses 18 Oktober 2013.

Nurkhasanah. 2006. Bahan Obat Alam Sumber Pendapatan Pembangunan: Fakultas Farmasi Universitas Ahmad Dahlan Yogyakarta.

Price,S.A\& L.MWilson. 1995.Patofisiologi Konsep Klinis. Edisi 4. (Alih Bahasa Peter Anugerah). Jakarta: Penerbit Buku Kedokteran EGC.

Primiani, 2011. Potensi Genistein pada Sistem Reproduksi Mencit (Mus musculus) Sebagai Penyusunan Bahan Ajar. Tesis tidak diterbitkan. Malang: Program Pasca Sarjana Universitas Negeri Malang.

Primiani, C.N. 2013. Potensi Umbi Bengkuang (Pachyrhizus erosus) terhadap Histologi Ovarium dan Uterus Mencit (Mus musculus) Premenopause. Prosiding Seminar Nasional IPA IV 27 April 2013. ISBN 97860299075
37 di Universitas Negeri Semarang 2013.

Puspasari D, 2007. Pengaruh Pemberian Ekstrak Kedelai Dosis Bertingkat Terhadap Morfologi Spermatozoa Mencit Jantan Strain Balb/C, Fakultas Kedokteran Universitas Dipanegoro Semarang.

Rishi, RK. 2002. Phytoestrogen in Health and Illness, Indian Journal of Pharmacology 34; 311-320.

Robinson, T. 1995. Kandungan Organik tumbuhan Tinggi, Penerjemah: Kosasih Padmawinata, Penerbit ITB, Bandung: hal. 191-216.

Ruggiero RJ, Pham D, Frances EL. 2002. Estrogen:Physiology, pharmacology, and formulations for replaceent therapy. J.Midwifery and Womens Health. 47(3):130-138.

Sari, Y., 2012. Efektifitas ekstrak biji bengkuang sbg larvasida nyamuk aedes aegepty L.instar III. Universitas Yogyakarta.

Suarsana Nyoman, 2011. Tepung Tempe Kaya Isoflavon Meningkatkan Kadar Kalsium, Posfor dan Estrogen Plasma Tikus Betina Normal. FKH ITB. Vol.12 No.3:229-234.

Watanabe S,Gang Zhoo V,Melby MK,Ishiwata N,Kimira M, 2006. Systematic review of intervention using isoflavon supplement and proposal for further studies.In : Sugono M,editor. Soy in health and disease prevention Boca Raton,Florida : CRC Press Taylor \& Francis Group LLC.

Wulandari S.H, \& Aulanni'am, 2010. Ekspresi Tumor Necrosis Factor (TNF-- $\alpha$ )dan gambaran histopatologi ginjl pada tikus (Rattus norvegicus) Renal Fibrosa Pasca Induksi Streptokinase. 
Santosa, Budi. 2009. Pengaruh Suplementasi Seng terhadap Kerusakan Tubukus Ginjala dan Sistem Hematopoiesis Tikus (Rattus nurvegicus) yang diberi Tawas. Program Pasca Sarjana Universitas Diponegoro.

Cotran R. S., Rennke H., Kumar V. 2007. Ginjal dan Sistem Penyalurnya. Dalam: Kumar V.,

Cotran R. S., Robbins S. L. (eds). Buku Ajar Patologi Robbins Volume 2. Edisi VII. Jakarta: EGC, pp: 572, 594-7.

Gultekin E., and Yildiz, F. (2006). Introduction to Phytoestrogen dalam Yildiz. F. Phytoestrogen in Functional Foods (pp.3-18). USA: CRC Press.

Prawiroharsono S. 2007. Prospek dan Pemanfaatan Isovlafon untuk
Kesehatan. Direktorat Teknologi Biondrusti, Badan Pengkajian dan Penerapan Pangan.

Hernawati, Potensi Buah Pare (Momordicha charantia L.) sebagai Herbal Antiinflamasi, Jurusan Pendidikan Biologi. FPMIPA Universitas Pendidikan Indonesia Julien Soepraptini1, Safda Farizy Ridho2, Koesnoto SP1. 2012. Gambaran Histopatologi Ginjal Tikus Putih Jantan pada Kasus Patah Tulang Femur dengan Terapi Ekstrak Tanaman Cissus quadrangularis dan Kalsium Karbonat Vol. 1, No. 1, Juli 2012 VetMedika J Klin Vet. 